\title{
Cross-Linguistic Evidence for Semantic Countability
}

\author{
Eun-Joo Kwak \\ Sejong University, Korea
}

\begin{abstract}
Countability and plurality (or singularity) are basically marked in syntax or morphology, and languages adopt different strategies in the mass-count distinction and number marking: plural marking, unmarked number marking, singularization, and different uses of classifiers. Diverse patterns of grammatical strategies are observed with cross-linguistic data in this study. Based on this, it is concluded that although countability is not solely determined by the semantic properties of nouns, it is much more affected by semantics than it appears. Moreover, semantic features of nouns are useful to account for apparent idiosyncratic behaviors of nouns and sentences.
\end{abstract}

Keywords: countability, plurality, countability shift, individuation, animacy, classifier

\footnotetext{
* This work is supported by the Sejong University Research Grant of 2013.

Eun-Joo Kwak

Department of English Language and Literature, Sejong University, Seoul, Korea Phone: +82-2-3408-3633; Email: ejkwak@sejong.ac.kr
}

Received August 14, 2014; Revised September 3, 2014; Accepted September 10, 2014. 


\section{Introduction}

The state of affairs in the real world may be delivered in a different way depending on the grammatical properties of languages. Nominal countability makes part of grammatical differences cross-linguistically, marked in various ways: plural (or singular) morphemes for nouns or verbs, distinct uses of determiners, and the occurrences of classifiers. Apparently, countability and plurality are mainly marked in syntax and morphology, so they may be understood as having less connection to the semantic features of nouns. However, a close scrutiny shows that semantics is deeply involved in the marking of countability and plurality.

If countability reflects semantic features of nouns well, it should be based on individuation. To be counted, objects need to be spatio-temporally separated from other entities and carry independent identities defined in the axes of space and time. In addition to spatio-temporal identities, individuation is also affected by other semantic features such as animacy, distinguishability, interaction with people.

Even if individuation affects countability, morpho-syntactic patterns that refect semantic features may not be identical. Hence, this study addresses how countability is affected by semantic features in diverse aspects: plural marking, unmarked number marking, singularization, the use of classifiers, and countability shift.

\section{Semantic Features Affecting Countability}

Although grammars allow different patterns depending on languages, countability is basically specified in syntax and morphology. However, it is discussed in much literature that 
countability is highly affected by semantic features of nouns. According to Quine (1960), count syntax is closely related to individuation, namely delimiting objects from other entities and defining their spatio-temporal identity. When objects do not take independent identities in the axes of space and time, they are not separated from other entities and thus hard to be counted.

Furthermore, Chierchia (2010) argues that although nominal countability is grammatically determined in principle, canonical mass nouns have a strongly tendency to be used as mass. They include nouns for substances, i.e., material aggregates which may be joined or split without changing their nature. More specifically, they include nouns for fluid (e.g., water, beer), paste (e.g., dough, clay), mineral (e.g., gold), and assorted material (e.g., wood, bronze, sand). Since the lack of spatio-temporal identity makes it hard to count, this group of nouns is mostly categorized as mass nouns in languages which allow the mass-count distinction.

Physical properties of objects are not the only semantic properties that affect countability. Smith-Stark (1974) and Corbett (1996, 2000) argue that the animate properties of entities play a crucial role in the mass-count distinction. They suggest an animacy hierarchy, where human nouns take the highest position and nouns denoting larger animals are more likely to take higher positions than nouns for smaller animals and inanimate objects.

speaker $>$ addressee $>$ 3rd person $>$ kin $>$ human $>$ animate $>$ inanimate

Figure 1. The Animacy Hierarchy (Corbett 2000)

They further argue that the animacy hierarchy is closely related to countability. Nouns taking high positions on the hierarchy are more likely to be count nouns. In other words, nouns denoting human beings have more potential to be count nouns than any other nouns. 
In addition to animacy, the perceptual or cognitive notion of distinguishability also affects countability. Wierzbicka (1988) argues that the more distinguishable entities nouns denote, the more likelihood they are categorized as count nouns. Because substances do not take independent spatio-temporal identities, they are less distinguishable than discrete objects. In this aspect, distinguishability seems to be directly connected with individuation. However, different degrees of distinguishability may be observed even for discrete objects. Although beans and grains of rice are possible to individuate physically, nouns for them may not be identical in countability. For instance, bean is count while rice is mass in English. Considering the fact that individual beans are easier to distinguish than individual grains of rice, their distinct countability naturally follows. The morpho-syntactic effect of distinguishability is further supported by the experiment of Middleton et al. (2004).

Finally, Wierzbicka (1988) argues that interaction patterns with people also affect the countability of nouns. In Polish, for example, the countability syntax of nouns denoting berries is different depending on people. Those who interact with individual berries, e.g., pick or eat berries, generally use count syntax. On the other hand, farmers, who interact with berries in quantities rather than individuals, usually use mass syntax for berry nouns. The semantic factor of interaction is also experimentally attested by Middleton et al. (2004).

\section{Plural Marking}

Not all languages allow the mass-count distinction in their grammars. When it is allowed, however, two morpho-syntactic mechanisms are mainly adopted. One is to induce number agreement by using specific morphemes on nouns, verbs, 
determiners, etc., and the other is to insert classifiers for mass nouns or to use separate categories of classifiers depending on countability. When additional morphemes are used to mark number, it is generally plural nouns or verbs that are accompanied by the morphemes. Singular nouns usually remain base forms without undergoing lexical changes or being co-occurred with number-marking morphemes.

When plural marking is coded grammatically, nouns which denote discrete objects may show different patterns. Corbett (2000) argues that nouns located in lower positions on the animacy hierarchy have lower potential to be plurally marked. This means that nouns for animals and inanimate objects are less likely to be marked distinctly in number.

The influence of the animacy hierarchy on plural marking is attested by diverse linguistic data.

In the vast majority of North American languages . . . only certain nouns have plural forms. In most of these, only nouns referring to human beings have plurals, or only some nouns referring to humans, often kin terms. (Multiple animals that are considered 'sentient beings,' such as pets or characters in legends, are also often referred to by plural noun.)

(Mithun 1988: 212)

Although plural nouns may undergo lexical changes in most North American languages, it is confined to a restricted group of nouns, namely nouns for humans or animals with high animacy. For example, in Slave, an Athabaskan language spoken in British Columbia and Alberta, Canada, a plural suffix ke may occur optionally with nouns denoting humans and dogs but never with nouns denoting inanimate entities (Rice 1989). Similarly, in Manchu, a Tungusic language of northern China, number is marked on pronouns and most nouns denoting humans (Corbett 2000). 
Even in the case that plurality is marked on verbs, the same preference is observed in some languages. In Mayali, a Gunwinjguan language of western Arnhem Land, Australia, number is marked on verbs which occur with human nouns or nouns for higher animates like spirits (Evans 1995).

When plural agreement occurs in a sentence, different degrees of animacy may determine morpho-syntactic forms. In Marind spoken in southern Irian Jaya, nouns are divided into four different categories (Foley 1986, Corbett 2000). Gender I includes nouns for male humans, gender II nouns for female humans and animals, and gender III \& V nouns for inanimates. To deliver plural readings, nouns in Marind show different morpho-syntactic patterns depending on their gender groups.

(1) a. i-pe patur/kivasom i-pe akik ka PL-DEF boy/daughter PL-DEF light.PL be 'those boys/daughters are light'

b. e-pe de e-pe akak ka III-DEF wood III-DEF light.III be 'that wood is light' or 'those pieces of wood are light'

c. i-pe behau i-pe akik ka IV-DEF pole IV-DEF light.IV be 'that pole is light' or 'those poles are light'

Patur 'boy' and kivasom 'daughter' are nouns categorized as gender I and II, respectively. In plural interpretations, they trigger plural agreement on determiners and predicates as exemplified in (1a). Contrastingly, gender III and IV include nouns denoting inanimates, which are located below animals on the animacy hierarchy. Because they have neither distinct plural forms nor plural agreement forms, singular and plural readings are not 
distinguished morpho-syntactically. Thus, (1b) and (1c) may be interpreted either singularly or plurally. In view of the fact that pieces of wood and poles are as discrete as humans, individuation via spatio-temporal delimitation is not a useful notion to account for the different patterns in (1). Hence, different degrees on the animacy hierarchy are proper a semantic factor to account for the differences.

Even if the singular-plural distinction is grammatically available, the frequency of number marking varies depending on semantic features. In Korean, count nouns may be followed by the plural morpheme -tul, which is optionally used. Even in the case that the occurrence of the plural morpheme is grammatically allowed, nouns for lower-positioned entities on the animacy hierarchy are less likely to be followed by the plural morpheme.

In Korean, nominal countability may be tested by the occurrence of -mata 'each' because it is restricted to count nouns only as shown by the contrasted grammaticality in (2a) (Kwak 2010, 2012).

(2) a. haksayng-mata/sakwa-mata/*mwul-mata student-each /apple-each /water-each 'each student / each apple / \#each water'

b. haksayng-tul/sakwa-tul/*mwul-tul student-PL /apple-PL/water-PL 'students/apples/\#waters'

Haksayng 'student' and sakwa 'apple' denote entities which are spatio-temporally delimited, which makes it natural for them to be followed by -mata. However, mwul 'water,' a substance noun, is hardly individuated, and thus it cannot be accompanied by -mata. The mass-count distinction shown in (2a) is parallel to the one in (2b), which shows contrasted grammaticality with the occurrence of the plural morpheme -tul. Only mwul is not allowed to occur 
with the plural morpheme.

In spite of the distinction shown in (2), plural marking on inanimate objects is less frequently observed in sentences.

(3) a. Haksayng-tul-i pointa. student-PL-NOM are-seen

'Students are seen.'

b. ??Sakwa-tul-ul sassta. apple-PL-ACC bought '(pro) bought apples.'

c. *Mwul-tul-i ssotacyessta. water-PL-NOM was-poured

'Water was poured.'

The occurrence of the plural morpheme -tul is natural with the human noun haksayng. However, its occurrence is less acceptable with the inanimate noun sakwa and quite awkward with the substance noun mwul. Although sakwa may occur with -tul as in (2b), its occurrence is not preferred in many sentences. Considering the fact that the semantic property of spatio-temporal discreteness sustains in (3), the animacy hierarchy seems to work in the contrast of naturalness in the sentences of (3).

\section{Unmarked Number Marking}

When number is marked morpho-syntactically, it is usually the plural that occurs with an additional morpheme or undergoes a lexical change. Hence, number marking generally means plural marking in most languages. In some languages, however, 
unmarked nominal forms are not always singular.

In Dagaare, a Gur language spoken in Niger-Congo, a specific morpheme $-r i$ is used to mark number, but it is not confined to plural nouns (Grimm 2012). ${ }^{1}$

(4)

$\begin{array}{llll}\text { Gloss } & \text { Stem } & \text { Singular } & \text { Plural } \\ \text { 'child' } & \text { bì- } & \text { bíé } & \text { bíírí } \\ \text { 'see' } & \text { bí- } & \text { bírì } & \text { bíè }\end{array}$

The same morpheme -ri is used to mark the plural form of 'child' and the singular form of 'seed.' In other words, the unmarked form in number is the singular noun bié for bì- 'child' while it is the plural noun bie for bí- 'seed.' When the morphological forms in (4) are glossed, they will have the pattern in (5).

\begin{tabular}{lll} 
Gloss & Singular & Plural \\
\hline 'child' & child & child-s \\
'seed' & seed-s & seed
\end{tabular}

Although unmarked nominal forms in number are fixed to the singular in most languages, they are changeable in Dagaare. Depending on lexical properties, either singular or plural nouns are followed by -ri. This kind of number marking is called inverse number marking.

The fieldwork of Grimm (2012) shows that unmarked number marking is affected by the semantic domains of nouns. Nouns for high-level animates are typically unmarked in the singular while nouns for low-level animates are typically unmarked in the plural. According to Grimm, the ratio between unmarked singular and

1 Although inverse number systems are not common, there are a few languages which are reported to have inverse number marking, including Kiowa spoken in North America and Nehan spoken in the Pacific. 
unmarked plural is as follows:

(6) mammal $>$ bird $>$ reptile $>$ insect $>$ vegetation

The ratio of nouns that are unmarked in the singular is highest in the semantic domain of mammals, and it decreases in nouns for birds and reptiles. The percentage of unmarked plural nouns is higher than that of unmarked singular nouns in the domains of insects and vegetation. This shows that Dagaare's number marking system is highly affected by animacy just as languages with plural marking. ${ }^{2}$

Animacy is not the only factor that influences on the determination of unmarked nominal forms in Dagaare. Trees and vegetables are understood to take the same position on the animacy hierarchy since they are inanimate. According to Grimm (2012), however, nouns for trees are generally unmarked in the singular whereas nouns for vegetation are typically unmarked in the plural. Considering the fact that trees are more distinguishable than vegetables, this distinction is naturally expected from the semantic properties of nouns, namely different degrees of distinguishability.

In addition to animacy and distinguishability, interaction with people also plays a role in the determination of unmarked nominal forms in Dagaare. Grimm (2012) observes that although nouns denoting tools are inanimate, they are usually unmarked in the singular. Obviously, nouns for tools are located in a lower position on the animacy hierarchy than those for insects. However, the ratio between unmarked singular and plural is reversed in these domains. The percentage of tool nouns unmarked in the singular

2 The influence of animacy on plural nouns is also demonstrated by different agreement prefixes for a demonstrative pronoun. Occurring with human plural nouns, the demonstrative pronoun -má is preceded by the prefix the prefix $b a-$. On the other hand, occurring with non-human plural nouns, it is preceded by $a$-. 
is much higher than that of unmarked singular insect nouns. This means that the number marking pattern of tool nouns is similar to that of mammal nouns. Then, animacy is not a relevant factor to explain unmarked number marking for tool nouns.

Grimm argues that tools are objects that interact with people more closely than other inanimates or low-level animates like insects. If we assume that interaction with people may also affect number marking, the idiosyncratic morphological behavior of tool nouns in Dagaare is easily accounted for.

\section{Languages without Number Marking}

Not all languages have a morpho-syntactic system to mark number in their grammar. Since only plural (or singular) nouns trigger number marking, the lack of number marking in a given language may lead to the belief that the mass-count distinction is not part of the grammar. However, the semantic notion of individuation is not irrelevant even in this case.

As early studies as in Quine (1969), languages are categorized into two groups depending on the way of counting number: classifier and non-classifier languages. In non-classifier languages like English, numeral expressions may combine with count nouns directly while they may need a classifier or container phrase for mass nouns. In classifier languages like Mandarin, countability may not be specifically marked, and classifiers are required for all or most nouns to combine with a numeral.

Generally, languages with a number-marking system are categorized as non-classifier languages. Hence, classification is considered as a separate notion from plurality and possibly from countability. This belief is strongly supported by Chierchia (1998a, b), arguing that nouns in classifier languages are not distinguished in countability and that they are all mass. Wilhelm (2008) 
challenges Chierchia's generalization with linguistic data in Dëne Suliné, a Northern Athapaskan language spoken in Northern Canada. Although Dëne does not have a number marking system morpho-syntactically, classifiers are not obligatory for nouns occurring with a numeral.

(7) solághe k’ásba

five chicken

'five chickens'

The numeral solághe 'five' directly combines with k'ásba 'chicken,' which patterns like count nouns in non-classifier languages like English. Given the fact that k'ásba is not plurally marked, the lack of classifier in (7) is rather unexpected. This unexpected structure, however, is not allowed to all nouns.

(8) solághe \#ejëretth’úé/\#bër/??tl'ólátúé five $\quad \mathrm{milk} / \mathrm{meat} / \mathrm{beer}$

(9) a. solághe ejëretth’úé trilı five milk container

'five cartons of milk'

b. solághe nedádhi bër five pound meat

'five pounds of meat'

c. solághe tutrli tl'ólátúé five bottle beer

'five bottles of beer'

The acceptability contrast shown in (8) and (9) shows that the nouns listed here do not yield numeral readings without a 
classifier. Notice that the nouns in (8) and (9) denote entities which are categorized as canonical mass without spatial-temporal delimitation.

Dëne provides interesting data as to countability. Although plurality is not marked in Dëne, classifiers are not obligatory in numeral readings just like other non-classifier languages. Moreover, the use of classifier is mandatory for nouns which are categorized as canonical mass nouns in non-classifier languages. Therefore, Wilhelm (2008) argues that mass and count nouns are distinguished in Dëne in spite of the lack of number marking. The obligatoriness of classifier shows whether given nouns are mass or count. Note that the semantic feature of individuation lies in the mass-count distinction in Dëne.

The role of individuation in the mass-count distinction of classifier languages is further attested by Mandarin, in which classifiers are mandatory for all nouns. At first, nouns do not appear to be distinguished in countability because they are all preceded by a classifier to be combined with a numeral. However, it is discussed in much literature that classifiers may be divided into mass and count by their semantic properties (Cheng \& Sybesma 1999; Chien, Barbara \& Chiang 2003). Count classifiers are related with the permanent properties of objects while mass classifiers concern temporary states of entities.

The countability of classifiers is further supported by different syntactic structures for them. The modification marker de may follow mass classifiers but not count classifiers (Cheng \& Sybesma 1999).
(10)
a. san
bang
(de) rou
three CL-pound
(de) meat
'three pounds of meat' 


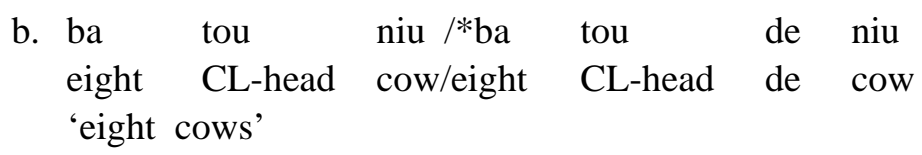

The denotation of rou 'meat' is canonical mass without spatio-temporal delimitation whereas niu 'cow' denotes discrete objects that take independent spatio-temporal identities. Similarly, bang for rou in (10a) is a mass classifier in its semantic property, denoting the temporary state of meat whereas tou for niu concerns the permanent property of cows, namely the individuality of cows. The semantic distinction of the nouns and the classifiers is correlated with the syntactic distinction. De is optionally used only with the mass classifier and the noun denoting canonically mass entities. Hence, Cheng \& Sybesma (1999) argues that the mass-count distinction is encoded in Mandarin in spite of the lack of the plural morphology. Countability distinguished by semantic features is further supported by Zhang (2007). Numeral classifiers in Mandarin have functions more than counting. They incorporate categorization parameters such as humanness, animacy, shape, function, consistency, and size.

\section{Countability Shift}

\subsection{Countability Shift by Mophology}

Basically, countability is lexically determined and morphosyntactically specified in sentences. However, countability may be subject to changes, which results in countability shift from mass to count or vice versa.

In Algonquian languages, genders divided by the animacy of nouns also convey information about countability. Nouns of animate gender are count whereas those of inanimate gender are 
mass. Although countability is lexically determined and divided by gender, it may be changed by gender morphology. $-i$ is used for inanimate marking on nouns and $-a$ for animate marking. When $-i$ is replaced by $-a$ and gender is shifted as a result, countability is also shifted from mass to count (Goddard 2002).
(11) a. zhooniyaah-i
(inanimate-mass collective noun) 'money/silver'
b. zhooniyaah-a 'a coin/a bill'
(animate-count singular noun)
c. zhooniyaah- $\boldsymbol{a}-\boldsymbol{k i}$ 'coins/bills'
(animate-count plural noun)

Zhooniyaah-i 'money/silver' in (11a) is inanimate, and thus it is a mass noun with a collective reading. When the inanimate morpheme $-i$ is replaced by $-a$ as in (11b), it is changed to a singular noun denoting an individual. Mathieu (2012) argues that the animate morpheme $-a$ functions as the singulative as in languages like Breton, Welsh, Arabic, and Dagaare. The singulative maps a mass or collective noun to a noun denoting a discrete individual or a noun with a measure reading based on a unit. The shift from mass/collective to count in Breton, Welsh, Arabic, and Dagaare is achieved by gender shift, namely from masculine to feminine. In contrast, Mathieu argues that the singulative in Algonquian languages induces gender shift from inanimate to animate, which has the effect of mapping mass nouns to count nouns. Once countability shift is achieved by the singulative, plurality is easy to be marked on nouns as in (11c).

Not only mass nouns with a collective readings, mass nouns with a substance reading are also subject to countability shift by gender shift. 
(12)
a. owiiyaas-i
(inanimate-mass noun)
'meat/flesh'
b. owiiyaas- $\boldsymbol{a}$
'a piece of meat'
(animate-count singular noun)
c. owiiyaas- $\boldsymbol{a - k \boldsymbol { i }}$
'pieces of meat'
(animate-count plural noun)

When a noun has a collective reading, the addition of the singulative morpheme induces an individual reading. On the other hand, the singulative on mass nouns as in (12b) and (12c) has a measure reading with the notion of unit.

Countability shift in Algonquian languages is quite productive and triggered by morphology. Apparently, semantic properties do not intervene in countability shift. According to Mathieu (2012), however, countability shift is not open to all mass nouns in Ojibwe, an Algonquian language. ${ }^{3}$ Although countability shift is quite productive by the singulative, there is a specific group of mass nouns that are not allowed to shift. Nouns for liquids are not allowed to occur with the singulative, and thus they do not have shifted counterpart. For example, liquid nouns such as bimide 'oil,' nbiish 'water,' miskwi 'blood,' and doodooshaaboo 'milk' cannot be followed by the animate morpheme. Thus, they are restricted to be used as mass. Note that liquid nouns make a representative group even in canonical mass nouns according to Chierchia (2010). Then, the idiosyncratic morphological behavior of liquid nouns in Ojibwe is naturally explained by the semantic properties of nouns. The denotation of a liquid noun is hard to delimit

3 According to Mathieu (2012), Ojibwe is quite similar to English in the morpho-syntax of number marking. Plurality is marked on nouns with a plural inflectional morpheme and triggers agreement on demonstratives and verbs. Plural morphemes may not occur inside compounds or inside derivational morphology. 
spatio-temporally due to its physical property. Hence, liquid nouns are exempt from the application of the singulative, which blocks the countability shift of the nouns.

\subsection{Countability Shift by Semantic Functions}

A morphological change is not a prerequisite in countability shift because countability may be shifted without any change in the lexical forms of nouns. Instead, it may be induced by semantic functions like the Universal Packager and the Universal Grinder (Pelletier 1975, Bunt 1985, Frisson \& Frazier 2005, Lima 2014).

Mass nouns are normally exempt from pluralization. Depending on contexts, however, mass nouns may be pluralized to deliver plural readings based on standard serving units. ${ }^{4}$ To induce countability shift from mass to count in this case, the Universal Packager is assumed to apply.

(13) I drank three beers.

In English, beer is a mass noun and cannot be pluralized. However, the pluralized beers in (13) is a count noun, interpreted as three units of beer, namely three glasses or bottles of beer depending on contexts.

4 When mass nouns are shifted to count nouns, universal packaging readings are not the only possibility.

(i) a. I drank three beers and enjoyed them all.

b. I tasted three beers and enjoyed them all.

Three beers in (ia) means three servings of beer whereas three beers in (ib) means three kinds of beer. The shifted reading in (ib) is the subkind reading of beer, which is derived by a separate function of the Universal Sorter (Pelletier 1975). When mass nouns are shifted to count nouns, either the Universal Packager or the Universal Sorter is applied to derive shifted readings. Which function is applied is determined by the context. 
Universal packaging readings are available when contexts provide standard serving units or conventionalized containers to package materials. This means that the availability of the Universal Packager is affected by culture. In much literature, it is argued that the Universal Packager is easy to apply in the domain of food and drink.

(14) a. ??I drank three waters.

b. \#I drank three bloods.

Although both beer and blood are liquid and thus identical in their physical shape, their shifted readings are different in naturalness. As shown by the contrast in (13) and (14), the packaged reading of blood is harder to accomplish than the packaged readings of beer and water. This is generally explained that standard serving units for blood are much harder to imagine in most contexts. However, when contexts are changed to the one where language speakers have more frequent chances to interact with blood in conventional serving units, the packaged reading of blood is much easier to get. The following passage is requoted from Lima (2014: 49).

. . . During this preliminary manipulation the bloods were exposed to the air and lost COT. Consequently, the reaction of the bloods at the beginning of incubation was somewhat more alkaline than normal blood. In four bloods measured, the plasma $\mathrm{pH}$ before incubation was 7.92, 7.87, 7.88, and 7.78 . . . (Requoted from Cajori \& Crouter 1924: 767)

Bloods in the bloods and four bloods means samples of blood in this passage. In this experimental context, a conventional serving unit for blood is much easier to obtain, which makes it natural to deliver its packaged reading. Hence, the semantic feature of interaction with people is useful to account for the different 
degrees of naturalness in the shifted readings. The more chances people have to interact with packaged individuals, the more natural their shifted readings are.

Countability shift is also possible from count to mass by the Universal Grinder, which takes objects and maps them to their material entities.

(15) a. There is apple in the soup.

b. ??There is table all over the floor.

For instance, apple in (15) does not mean a single apple in the soup. Rather, it is construed as the material of apple which is part of the soup. Apple in (15a) is a mass noun shifted by the Universal Grinder. Although the material reading of apple in (15a) is natural, the material reading of table in (15b) is quite awkward. Again, the availability of the Universal Grinder is distinct depending on the semantic properties of nouns. To account for this distinction, Chierchia (2010) argues that the number of contexts which allow shifted readings determines the acceptability of the readings. There will be many contexts which trigger the material reading of apple, but it is not easy to make up a context where table needs to be grinded to deliver a material reading. Again, how many chances people have to interact with grinded materials determines how natural shifted readings are.

\section{Conclusions}

Basically, the mass-count distinction is lexically determined and specified in syntax or morphology. Thus, it may appear that semantics has no relation to countability. However, semantic properties influence on countability much more pervasively than expected. Semantically, nouns may be divided by the semantic 
property of individuation depending on whether they denote entities which are spatio-temporally delimited. Individuation may be affected by other semantic features such as animacy, distinguishability, and interaction with people. These semantic features are reflected on the mass-count distinction.

Cross-linguistically, countability is specified in diverse ways: plural marking, unmarked number marking, singularization, and different uses of classifiers. In contrast with the diverse patterns of countability and plurality (or singularity) marked in syntax and morphology, the semantic features of nouns are more in common cross-linguistically. Hence, they are useful to account for both categorized and idiosyncratic behaviors of nouns and sentences.

In this study, we have observed various patterns of the mass-count distinction and number marking cross-linguistically. Although grammatical strategies are quite distinct depending on languages, there is a strong tendency to distinguish mass and count nouns. Moreover, countability and plurality (or singularity) are highly affected by the semantic properties of nouns. Apparent idiosyncratic patterns shown in syntax or morphology are categorized well and explained systematically when semantic features are considered. Therefore, we have concluded that although it may not be the only dimension, the role of semantics is quite robust in the mass-count distinction and number marking.

\section{References}

Bunt, H. 1985. The Formal Representation of (Quasi-)Continuous Concepts. In J. Hobbs \& R. Moore (eds.), Formal Theories of the Common Sense World 37-70. Norwood, NJ: Ablex.

Cajori, F. \& C. Crouter. 1924. A Comparison of the Rate of Glycolysis in Different Bloods with Special Reference to Diabetic Blood. The Journal of Biological Chemistry 60, 
765-775.

Cheng, L. \& R. Sybesma. 1999. Bare and Not-So-Bare Nouns and the Structure of NP. Linguistic Inquiry 30, 509-542.

Chien, Y., L. Barbara \& C. Chiang. 2003. Chinese Children Comprehension of Count Classifiers and Mass Classifiers. Journal of East Asian Linguistics 12, 91-120.

Chierchia, G. 1998a. Plurality of Mass Nouns and the Notion of Semantic Parameter. In S. Rothstein (ed.), Events and Grammar 53-103. Dordrecht: Kluwer. . 1998b. Reference to Kinds across Languages. Language and Semantics 6, 339-405. . 2010. Mass Nouns, Vagueness, and Semantic Variation. Synthese 174, 99-149.

Corbett, G. 1996. Minor Number and the Plurality Split. Rivista di linguistica 8, 101-122. 2000. Number. Cambridge: Cambridge University Press.

Evans, N. 1995. A-Quantifiers and Scope in Mayali. In E. Bach et al. (eds.), Quantification in Natural Languages I 207-270. Dordrecht: Kluwer.

Foley, W. 1986. The Papuan Languages of New Guinea. Cambridge: Cambridge University Press.

Frisson, S. \& L. Frazier. 2005. Carving Up Word Meanings: Portioning and Grinding. Journal of Memory and Language 53, 277-291.

Goddard, I. 2002. Grammatical Gender in Algonquian. In H. Wolfart (ed.), Papers of the 33rd Algonquian Conference 195-231. Winnipeg: University of Manitoba.

Grimm, S. 2012. Individuation and Inverse Number Marking in Dagaare. In D. Massam (ed.), Count and Mass across Languages 75-98. Oxford: Oxford University Press.

Kwak, E. 2010. The Distributivity of Collection Terms in Korean. Journal of Language and Translation (Now Called Journal of Universal Language) 11.2, 179-205. . 2012. Typological Accounts for Nominal Forms. Journal of 
Universal Language 13.1, 101-123.

Lima, S. 2014. The Grammar of Individuation and Counting. Ph.

D. Dissertation. Amherst, MA: University of Massachusetts.

Mathieu, E. 2012. On the Mass/Count Distinction in Ojibwe. In D.

Massam (ed.), Count and Mass across Languages 172-198.

Oxford: Oxford University Press.

Middleton, E. et al. 2004. Separating the Chaff from the Oats:

Evidence for a Conceptual Distinction between Count Noun and Mass Noun Aggregates. Journal of Memory and Language 50, 371-394.

Mithun, M. 1988. Lexical Categories and the Evolution of Number

Marking. In M. Hammond \& M. Noonan (eds.), Theoretical Morphology: Approaches in Modern Linguistics 211-234. San Diego, CA: Academic Press.

Pelletier, F. 1975. Non-Singular Reference: Some Preliminaries. Philosophia 5, 451-465.

Quine, V. 1960. Word and Object. Cambridge, MA: MIT Press. . 1969. Ontological Relativity and Other Essays. New York:

Columbia University Press.

Rice, K. 1989. A Grammar of Slave. Berlin: Mouton de Gruyter. Smith-Stark, T. 1974. The Plurality Split. In M. LaGaly, R. Fox

\& A. Bruck (eds.), Papers from the 10th Regional Meeting 657-671. Cambridge: Cambridge University Press.

Wierzbicka, A. 1988. The Semantics of Grammar. Amsterdam: John Benjamins.

Wilhelm, A. 2008. Bare Nouns and Number in Dëne Suliné. Natural Language Semantics 16, 39-68.

Zhang, H. 2007. Numeral Classifiers in Mandarin Chinese. Journal of East Asian Linguistics 16, 43-59. 